\title{
Thoracic Vagal Ganglion and Referred Craniofacial Pain: a Case Report and Review
}

\author{
Ganglio Torácico Vagal y Dolor Craneofacial Referido: Reporte de Caso y Revisión \\ "Luis Miguel Ramírez Aristeguieta; *'Luis Ernesto Ballesteros; ${ }^{* * * *}$ Pedro Luis Forero \& ${ }^{* * * *}$ Carlos Conde
}

RAMIREZ, A. L. M.; BALLESTEROS, L. E.: FORERO, P. L. \& CONDE, C. Thoracic vagal ganglion and referred craniofacial pain: a case report and review. Int. J. Morphol., 25(1):33-42, 2007.

SUMMARY: The presence of a ganglion-like tumefaction is reported in the mediastinal course of the right vagus nerve at T1 level in a cadaver in the Universidad Industrial de Santander's morphology laboratory. The vagal ganglion was located next to hyperplasic lymphoid nodes in para-tracheal and tracheal-bronchial levels, agglomerating in a large lymphoid mass in the carina and the pulmonary hilum. Anatomical-pathological study revealed a marked, diffusely distributed, predominantly histo-lymphocyte mixed inflammation, separating the epineurium, producing lysis of the vagus nerve fibers. This finding showed the degeneration of this cranial par by mediastinal pathology. This provided a possible explanation for the physiopathology of pain referring to the head and neck in inflammatory or neoplastic pathology involving compression and degeneration by inflammatory infiltration of the vagus nerve. Pons-medullar trigeminal afferent tracts and connectivity, supra-spinal pathways for processing somatic-visceral pain, possible somatic-vegetative responses and the integration of the trigeminal system in the physiology of pain concerning the vagus nerve are all discussed.

KEY WORDS: Visceroception; Heterotopic pain; Inferior ganglion of vagus nerve; Paratrigeminal nucleus; Trigeminal subnucleus. caudalis.

\section{INTRODUCTION}

Diagnosing craniofacial pain is complex due to its multi-causal origin, such as traumatic, metastatic, musculoskeletal, inflammatory, infectious and viral disorders; such situation assumes greater nuances when pain is chronic, deep and heterotopic. Complaints regarding this type of pain do not normally help much in diagnosis since their origin does not often coincide with their localization. Craniofacial pain can be expressed in terms of a succinct definition of pain to a wide range of dysesthetic and paresthetic sensations (Lund et al., 2001). If such pain and its localization is already complex, then involving extraterritorial areas apart from the head and neck such as the thoracic mediastinum further complicate its diagnosis.

Referred craniofacial pain arising from neoplastic masses in the mediastinum (even though rarely appearing) has been reported in 35 patients to date. (Jones \& Lawson, 1987; Bindoff \& Heseltine, 1988; Nestor, 1991; Broux 1991;
Bongers et al., 1992; Schoenen et al., 1992; Nestor \& Ngo, 1994; Capobianco, 1995; Shakespeare \& Stevens, 1996; Goldberg, 1997; Abraham et al., 2003; Sarlani et al., 2003; Eross et al., 2003; Demez et al., 2004; Palmieri, 2006). However, the central connections responsible for referred pain in such clinical cases have not been thoroughly reviewed. Des Prez \& Freemon (1983) reported the case of a woman suffering from craniofacial pain caused by lung cancer in 1983 and its relief following vagotomy. The possibility of craniofacial pain being referred by lung cancer has been considered since 1927 (Fay, 1932). Pain referred to the craniofacial and cervical area is severely intense and episodic, constant or paroxysmal, depending on the pathology's stage. It mainly involves the ear (and peri-auricular area), temporal area, mandible, temporomandibular joint, maxilla, cheek, teeth, face, nose, eyes, neck, oropharynx, mastoid area, forehead and shoulder. Such pain is usually badly diagnosed as being persistent idiopathic fa-

\footnotetext{
Odontology, Prosthetic Dentistry and Temporomandibular Disorders. Associate Professor of Morphology, Department of Basic Sciences, Medicine Faculty, Universidad Industrial de Santander, Bucaramanga, Colombia.

* Medical Doctor, Anatomy Degree. Basic Sciences Department Director, Professor, Medicine Faculty, Universidad Industrial de Santander, Colombia.

*** Pathologist, Basic Sciences Department Professor, Medicine Faculty, Universidad Industrial de Santander, Colombia.

**** Neurophysiologist, PhD. Basic Sciences Department Professor, Medicine Faculty, Universidad Industrial de Santander, Colombia.
} 
cial pain, a temporomandibular disorder, neuralgia and/or odontalgia. Symptomatology can be ipsilateral or bilateral to the tumoural mass, depending on the pathology's extension; it is predominantly right-hand sided since the lefthand side vagus passes more in front of the large vessels and is less exposed than the right-hand one which is more related to the trachea and lymphatic nodes.

The functioning of the vagus nerve and its systemic effects are transcendent. Important functions are derived from the vagus nerve's abundant connections such as respiratory functions, circulatory homeostasis, immune response and visceral control from peripheral stimuli. Afferent information from the lungs during the respiratory cycle and the stomach due to chemical discharge and mechanical, nutritional and immune stimuli has a notable concomitance with pain and the cognitive-behavioral dimension (Berthoud \& Neuhuber, 2000). Its modulator effect on somatic and visceral pain is related to central opioid anti-nociceptive functions (facilitating endogenous analgesia) and segmental inhibition of peripheral pain and the inflammatory response by recruiting descendent modulator tracts (Sandkuhler, 1996; Than et al., 2000; Miao et al., 2003; Kirchner et al., 2006). The contrary effect or facilitation of somatic and sympatheticvisceral pain is produced after vagotomy or low intensity vagal electrical stimulation having pro-nociceptive or

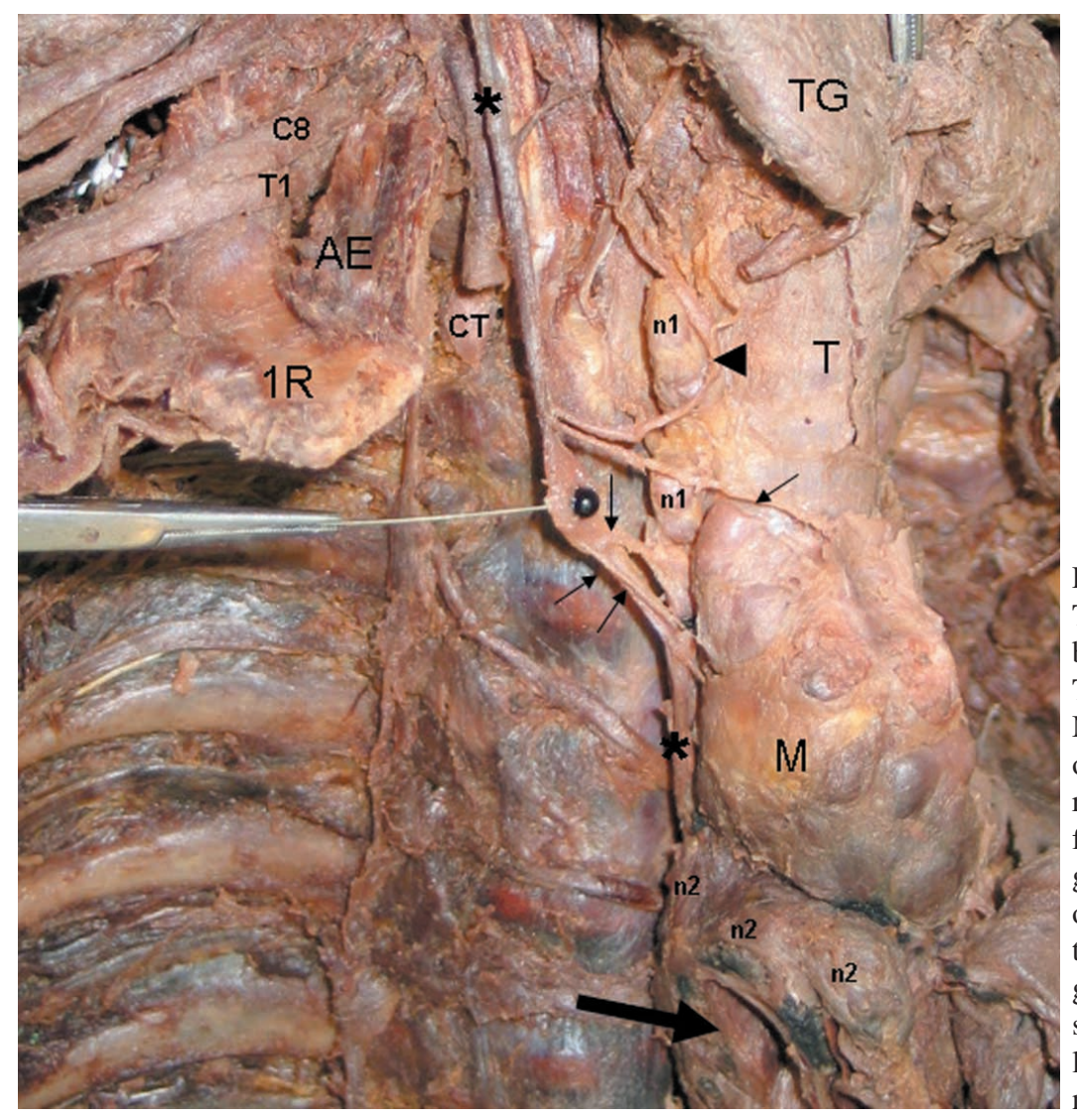

biphasic effects (Randich \& Gebhart, 1992; Bossut \& Maixner, 1996; Ness et al., 2000). Treating behavior and refractory seizure episodes have been studied together with pain following electrical stimulation of the vagus nerve with promising results (Dodrill \& Morris, 2001; Barry et al., 2004; Wheless \& Baumgartner, 2004; Casazza et al., 2006).

It seems that the reception of pain corresponding to the vagus is not conscious and does not modulate discriminatory sensory aspects (intensity, localization and duration) since this is more related to the emotional-affective dimension (autonomic responses and emotional reactions) and this perhaps leads to its modulating effect on behavior. The solitary nucleus (the main vagus afferent receptor) is a key structure in somatic-visceral processing, including pain. It is connected to the limbic system via several nuclei: paratrigeminal (a new integrant of the central pain modulating system), trigeminal subnucleus caudalis, parabrachial, reticular dorsal nucleus, Kolliker-Fuse, locus ceruleus and finally with thalamus, incerta area, hypothalamus (ventro-medial and posterior nucleus), amygdala nucleus, cingulate and insular cortex. Such connections produce effects on the motivational-affective and evaluative-cognitive dimension of pain (Melzack, 1999; Almeida et al., 2002). Many studies have been done respecting a pain neuromatrix model in which the emotional 


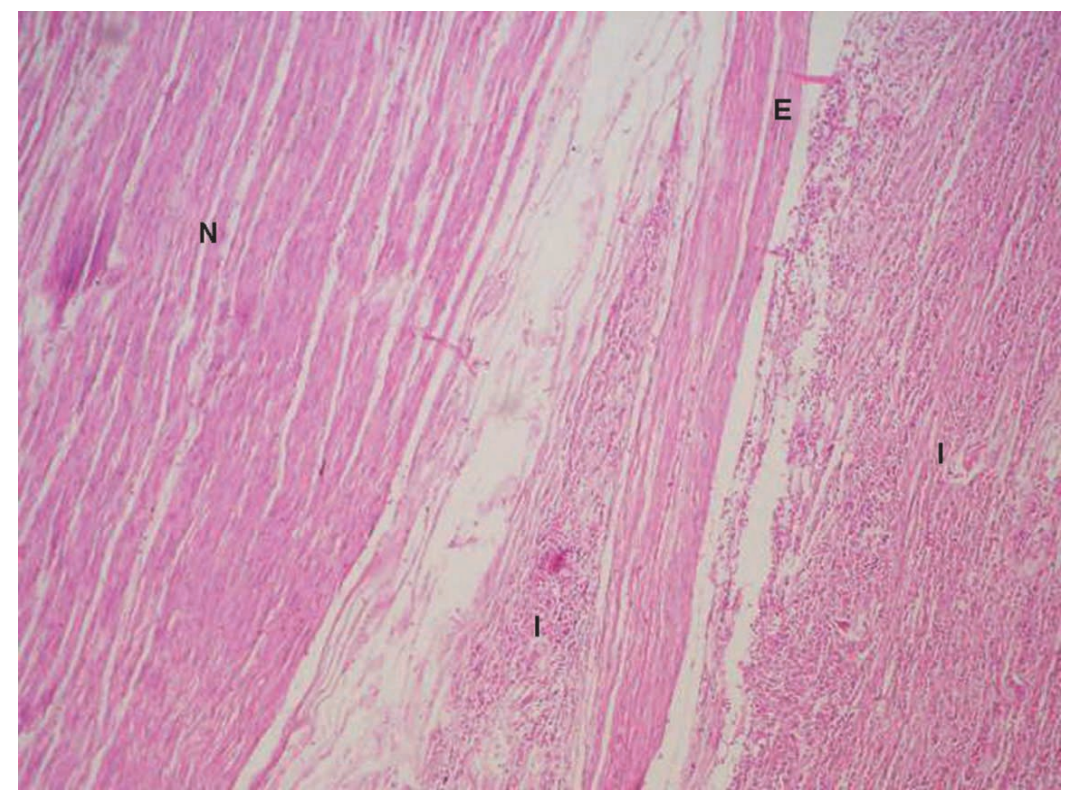

Fig. 2. Histopathological study of the vagus ganglion-like mass in which nerve fillet was observed, with diffusely distributed, predominantly polymorphous-nuclear and histiocyte marked mixed inflammatory infiltrate, compromising the epineurium with autolysis and fibrosis. N. Vagus nerve. E. Infiltrated epineurium. I: Inflammatory infiltrate.

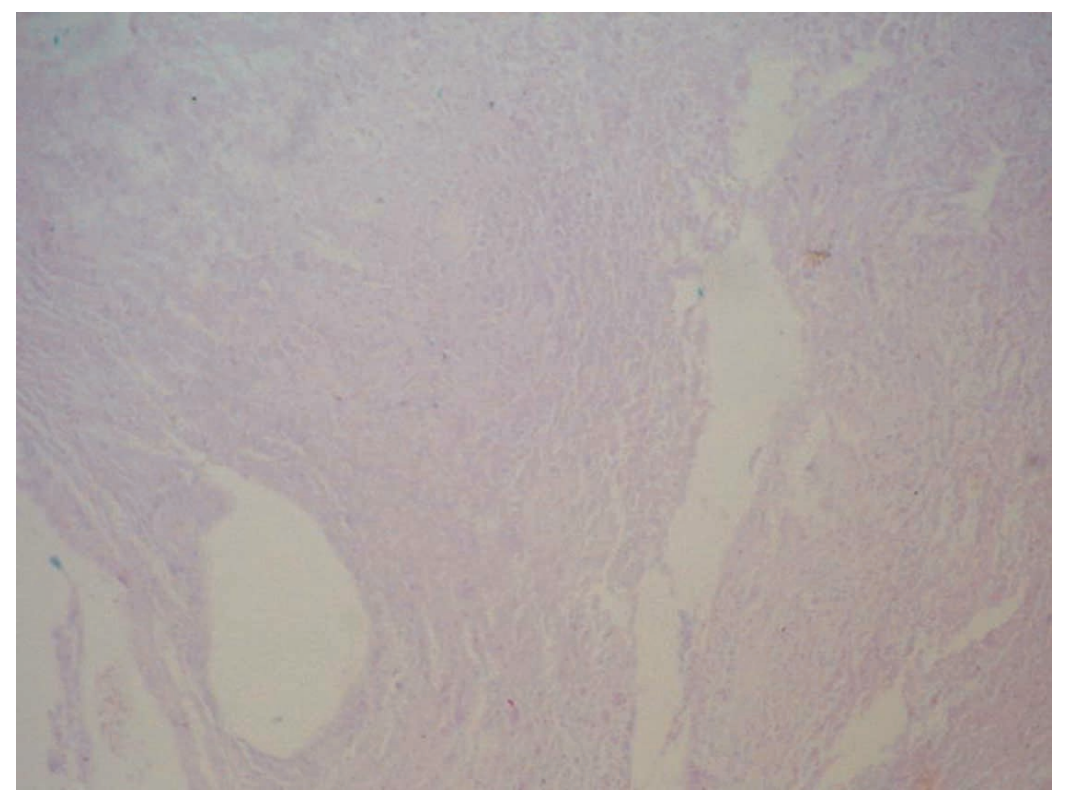

Fig. 3. Negative Zinn Nielsen staining. No alcohol-resistant bacilli were observed in the staining.

This case-report shows the vagus nerve's commitment in mediastinal pathology. Heterotopic pain in the head and neck from apparently far-removed areas (but intricately linked by common central thermoalgesic domains) could explain possible referred and extraterritorial pain mechanisms. Even though the question persists in relation to how vagal damage from extra-cranial levels could produce craniofacial pain, the possible physiopathology of lesions at this level is discussed, as is its association with referred pain.

\section{CASE DESCRIPTION}

A cadaver was observed in the Universidad Industrial de Santander's Morphological Medicine Laboratory (Bucaramanga, Colombia) having a firm nervous ganglion-like tumefaction ( $1.5 \mathrm{x}$ $0.8 \times 0.3 \mathrm{~cm}$ ) on the right vagus nerve at superior mediastinal level (Fig. 1). This structure was found to be surrounded by multiple lymphoid masses at para-tracheal and tracheal-bronchial level and to be close to a large lymphatic mass near the carina. Anatomical-pathological study of this vagus nerve entumesence revealed a nervous fillet having marked, predominantly polymorpho-nuclear and histiocyte, mixed, inflammatory infiltrate which was diffusely distributed, compromising the epineurium. Areas having autolysis and fibrosis were also observed. No viable tumoural cells were recognized (Fig. 2).

Ganglion conglomerates corresponded to a chronic granulomatous process, having extensive necrotic areas; ganglion tissue with loss of its architecture, abundant caseous necrosis, autolysis and fibrosis were found in them. Inflammatory histio-plasmo-lymphocyte infiltrate was also found, located on the periphery of the lesion. There were no multinucleated Langhan's cells or foreign bodies. No tumoural lesions were recognized in the material so examined. No alcohol-resistant bacilli were observed in Zinn Nielsen staining (Fig. 3). Assuming mediastinal tumors' morphological nature, the first diagnosis option regarding bronchogenic carcinoma was discarded due to the lack of compromise of bronchial-pulmonary structures. The mediastinal mass's morphological characteristics corresponding to a ganglion-like conglomerate (lymphoids being firmly bound by a fibroid covering being recognized in these multiple nodes, thereby facilitating their enucleation) suggested a granulomatous inflammatory process corresponding to possible tuberculosis. 


\section{DISCUSSION}

The vagus nerve has admirable anatomy due to its multi-configuration and its multi-functionality. This nerve has $80 \%$ parasympathetic pre-ganglion visceral-motor fibers, the remaining $20 \%$ consisting of somatic-motor efferents (10-20\%) and general visceral afferents (80-90\%) (Holzer, 1998). Its soma are found in the vagus' dorsal nucleus and ambiguus nucleus forming an intricate, multiple-level, inter-neuronal network. These involve several nuclei: the para-brachial and Kolliker-Fuse, solitary, dorsal vagus, paratrigeminal (PA5), trigeminal subnucleus caudalis (SC5), raphe magnus, area postrema and medial and lateral reticular nuclei in the medulla oblongata and pons (rostro-ventro-lateral and lateral). The vagus' visceral information is important for maintaining the reflexes conserving homeostatic functions and which are coordinated together with talking, masticatory-deglutitoryrespiratory, pain modulation, cardio-pulmonary, vasopressor, secretomotor and somatomotor mechanism complexes; trigeminal afferents participating in vegetative, gustatory, pneumotaxic and cardio-respiratory centers (Kalia \& Mesulman, 1980; Stuesse et al., 1984; Bon et al., 1997; Armstrong \& Hopkins, 1998; Saxon \& Hopkins, 1998; Ruggiero et al., 2000; Caous et al., 2001; Sato \& MomoseSato, 2004; Afifi \& Bergman, 2005; Kobayashi et al., 2005). The vagus' afferents mostly reach the solitary nucleus, the rest the vagal dorsal nucleus and PA5 and SC5 nuclei. Intermedius, glossopharyngeal and trigeminal afferents also reach the solitary nucleus. Trigeminal solitary and spinal nuclei are shared by four cranial pairs, reciprocally interconnecting afferents and efferents with PA5 in a somatic-visceral integration complex modulating cardiovascular and nociceptive functions (Beckstead \& Norgren, 1979; de Sousa et al., 2001).

Being the tenth cranial pair, the vagal nerve's anatomical routing shares wide-ranging territory, beginning in the head, passing through the neck and mediastinum, ending in the abdominal viscera. During its course from its apparent origin in the medulla oblongata, it only presents two evident ganglions at the base of the cranium: one which is superior and internal to the cranium or "superior ganglion" receiving general somatic afferents and one which is inferior and external to the cranium or "inferior ganglion" to which general visceral afferents reach. Innervation of the meninges in the posterior cranial fossa, the tympanum, external auditory canal in its posterior-inferior area, the concha and part of the auricle's cutaneous territory has been attributed to it in the head and neck, together with the cervical branches.

Aerodigestive territory (pharyngeal plexus) also receives its sensory support, together with special innervation for taste, in the posterior area of the tongue and epiglottis. It innervates the cricothyroid muscle and partially innervates the arytenoids of the larynx and a portion of the laryngeal mucosa. The recurrent laryngeal nerve, innervating the larynx's intrinsic muscles, accompanies the vagus during its descending route in the neck and then separates from it. It should be stressed that it begins to have cardiac branches in the neck which will then become introduced into the mediastinum. Some of these branches, together with the glossopharyngeal nerve, carry out chemoreceptor and baroreceptor functions in the carotid glomus and sinus, respectively. The cardiac branches form a network with the pulmonary branches in the base of the neck and thorax to provide the parasympathetic innervation of the cardio-pulmonary complex and multiple esophageal bilateral ramifications in the diaphragm where the right-hand and lefthand vagus rotates clockwise to continue to the abdomen. The vagus branches in the anterior and posterior nervous plexus in the abdomen to innervate adnexa organs and the small and large intestine, except for the descending colon, sigmoid, rectum and pelvic organs. It contains multiple, small paraganglions throughout its thoraco-abdominal course (glomus cells in the fibers) (Kirchner et al.; Williams et al., 1989).

Case-reports concerning mediastinal pathologies have usually considered damage to the vagus to be caused by mechanical compression due to extrinsic lymphatic invasion (Bindoff \& Hesseltine). This case presents intrinsic mechanical compression of the epineurium, with consequent nervous degeneration of the vagus nerve. Damage to the fibers of this cranial pair could injure caudal efferents from the level of the lesion, thereby affecting the respiratory system (HeringBreuer's reflex), cardiovascular control and gastrointestinal function. It could also conduct painful rostral stimuli from the same site as that demonstrated in case reports of craniofacial referred pain from the mediastinum (Jones \& Lawson; Bindoff \& Heseltine; Nestor; Broux; Bongers et al.; Schoenen et al.; Nestor \& Ngo; Capobianco; Shakespeare Stevens; Goldberg; Abraham et al.; Sarlani et al.; Eross et al.; Demez et al.; Palmieri \& Freemon; Des Prez et al.; Fay. Regarding abdominal and mediastinal pain, this pair's great visceroceptive sensory ability should be taken into account. Retrograde labeling techniques have been used to demonstrate how interoceptive afferents of pain in the vagus are conducted in a greater ratio (2:1), compared to medullar segment ganglions corresponding to the sympathetic system. Formerly such conduction of visceral pain was only related to the spinosolitary tract amongst other less well defined ones (spinalreticular lateral, spinal-pontine-mesencephalic, spinalhypothalamic and spinal-amygdaloid) (Traub et al.,1996).

Sarlani et al. attribute symptomatology referred in the head to "paraneoplastic syndrome" (autoimmune disorders), being secondary to malign tumor cells' circulating humoral 
factors at mediastinal level. However, the expansion of pain, the reduction of its threshold and increased peripheral neuron discharge could obey the "convergence" of somatic-visceral thermal and painful signal in the same area of the trigeminal nerve's spinal nuclear complex via the vagal tract. Thermoalgesic signals from C3, C2, C1 (occasionally), X, IX, intermedius, and V converge in PA5 and SC5 and are then become segmented over a wide, heterogeneous area of the central nervous system (Marfurt \& Rajchert, 1991). Plasticity and hyper-excitation may be obtained in this area in the presence of chronic, deep stimuli which may lead to erroneous localization of pain signals' origin in the somaticsensory cortex, due to making neuronal afferents related to other localizations much more sensitive (Bindoff \& Heseltine; Sessle, 2000). For example, otalgia is a very common symptom in craniofacial pain involving these cranial pairs and cervical segments.

Damage to the vagus at mediastinal level sends pain signals to the spinal trigeminal nuclear group, unleashing referred pain. Not much research has related the vagus nerve's interoceptive pain and trigeminal intero-exteroceptive pain into its segmental and supra-segmental tracts. Somatic and visceral pain's structures and pathways have normally been considered separately, without their interaction having been born in mind to date. A valuable set of publications have used neuron tracing techniques to demonstrate how the somaticvisceral afferents of pain in the vagus also include PA5 and SC5, starting in the varied connections of the inferior and superior ganglions of the vagus which become centrally mixed (Caous et al.; Nasution \& Shigenaga, 1987; Saxon \& Holpkins, 1998; Li et al., 1999).

The PA5 nucleus serves as a critical medullar relay in integrating and regulating viscero-visceral, somato-sensory, somato-visceral, secretomotor, chemo-barometric, cardiovascular, respiratory, nasopharyngeal, gustatory and thermo-regulative reflex arcs. PA5 is a small diffuse collection (6 mm in humans) of neurons and neuropils located dorsolaterally to the spinal trigeminal nucleus and between the interpolar subnucleus and SC5, having bilateral modulator connections at bulbar, pontine and thalamic level. This nucleus forms part of another four nuclei from the spinal trigeminal tract's interstitial system (Cajal's interstitial islands) even though some consider it to be a rostral extension of SC5 (Phelan \& Falls, 1989, 1991). It is found to be immersed in the trigeminal tract and shares similar thermo-algesic functions due to its closeness to SC5. As well as being interrelated to vegetative activity and motor coordination of talking and deglution, it has also been attributed with regulating bloodpressure, controlling visceral pain, thermal regulation and motivational-affective responses to pain due to its connections with the solitary nucleus, raphe magnus, parabrachial area and amygdaloid nucleus (trigeminal-parabrachial-amygdaloid ipsilateral tract) with its usual visceral, nutritional (anorexia), respiratory, thermal and inhibitory descending pain effects (Caous et al.; Armstrong \& Holpkins; Jasmin et al.,1997; Paues et al., 2006; Rybka \& McCulloch, 2006).

The importance of PA5, related to nocifensive, nociceptive, modulator response and referred pain, lies in the fact that it is a direct relay for somatic-visceral nociceptive afferents of V, intermedius, IX, X pairs and rostral medullar segments to C7. These afferents reach this nucleus' neuropil, overlapping it (without interneurons) and making a connection with structures related to autonomous control of the pons and medulla oblongata, but also directing themselves towards SC5, thereby interrelating themselves with trigeminal dynamics of pain in the head and neck (Caous et al.; Bon et al.; Saxon \& Holpkins, 1998, 2006; Armstrong \& Hopkins; Lindsey et al.,1997; Lapa \& Watanabe, 2005). The vagus nerve's pain afferents (parasympathetic) are complemented by a profuse medullar network (sympatheticsomatic) coupling the neuroaxis' pain pathways to those of the vagus, these being finally added to facilitator or inhibitory integration of subcortical and cortical pain sensation.

Nociceptive visceral afferents of the vagus (like those visceral conducted by the medulla) mostly reach the solitary nucleus. Pain signals from the vagus also direct a tract towards PA5 and SC5 in a lateral pathway (homologous to the solitary-trigeminal tract in the rat) (Gwyn et al., 1985; Menetrey et al., 1992; Gieroba \& Blessing, 1994; YousfiMalki \& Puizillout, 1994). The thermoalgesic visceral afferents of the abdomen and mediastinum sharing a pathway with the vagus become integrated with the trigeminal nuclear complex and its pain modulating territory via PA5 and SC5 and have an inhibitory medullar segmental effect via the solitary-spinal tract (Randich \& Gebhart; Mtui et al., 1995). In 1956 Wand-Tetley observed how stimulation in a receptive area could inhibit pain in an area distant to this (contra-irritation or diffuse noxious inhibitory control) and how this modulator interaction also happens somatoviscerally and viscero-somatically (Ness \& Gebhart, 1991a,b). It should be stressed that from this modulation that painful stimulus is encoded by multiple central endogenous networks having pronociceptive and antinociceptive neuronal and hormonal properties and that they are produced from the final product of the sum of facilitating and inhibiting synaptic influences throughout the whole of its ascendant pathway.

It is also interesting that synapsis afferents reaching the solitary nucleus happens again to the PA5 connecting reciprocally ipsi- and contra-laterally with solitary, parabrachial, dorsal vagus, caudal medullar dorsal horn, C1 
and $\mathrm{C} 2$ ventral medullar horns (the accessory's spinal nucleus portion) and SC5 nuclei (Jou et al., 2002). The foregoing are alternately and concomitantly related to the vagus (solitary) and trigeminal (PA5). Afferents from all medullar segments have also been attributed to PA5 which are not just limited to craniofacial pain and seem like the old spinal-parabrachial tract (trigeminal-parabrachial) in vegetative regulation, demonstrating the importance of the trigeminal in relaying pain's somatic-visceral reflexes (Ruggiero et al.; Bon et al.; Jasmin et al.; Saper, 1995; Carstens et al., 1995). Phelan \& Falls, used neuronal tracing techniques to show how the spinal trigeminal complex receives ipsilateral sensory afferent information from the medullar segments and also sends efferents towards them by integrating spino-trigeminal and trigemino-spinal tracts. The foregoing is very significant and reinforces the trigeminal complex's importance in the complicated medullar and vagal sensory pathways' pontinemedullar interaction. PA5 and SC5 signals ascend (mostly) to the contralateral ventral-postero-medial thalamus via the trigemino-thalamic tract to then be expressed in the somatosensory cortex (Li et al., 1999; Caous et al.). These shared tracts and common neurological territories give heterotopic symptomatology prominence due to central excitation's effect in the presence of chronic and deep pain (Saxon \& Hopkins; Gwyn et al.; Saper; Li et al., 1996).

A large territory becomes excluded when the vagus's visceral signals related to the trigeminal nerve are only considered at pharyngeal and larynx level. This discarded territory emits signals converging from mediastinal (heart, lungs, and esophagus) and abdominal levels (esophagus, liver, spleen, pancreas, stomach, duodenum, jejunum, ileum and ascendant and transverse colon) (Hisata et al., 2006). Fay suggested that this connectivity was viable when the vagus was stimulated during surgery and obtained pain in the tongue, pharynges and ear. Abdominal visceral "pain" afferents (stretching, heat, ischemia, laceration), as well as being conducted by the sympathetic system, usually and mostly travel via the vagus nerve, synapsis happening in the inferior ganglion and converging (as well as the solitary nucleus) towards PA5 and SC5 nuclei. These signals reach the thalamus from trigeminal territory, thereby seeming to link the vagus and the trigeminal in the multi-causality and extra-territoriality of craniofacial and thoracic-abdominal referred pain (Caous et al.; Bon et al.; Monconduit et al., 2003; Culberson \& Kimmel, 1972; Contreras et al.,1982). The convergence of visceral and somatic pain with the same neurons from the trigeminal sensory tract (SC5 and PA5) is the key element explaining the neural basis for referred pain's clinical phenomenon, originating in the visceral organs.

The whole course of the vagus nerve must be considered in the presence of craniofacial pain and also the possibility that it has been irritated by pathological processes at thoracic cavity and abdominal levels. Even though it has not been attributed with pain reception ability in the past, it has been shown that it is cranial pair having multiple functions. Symptoms or essential signs are frequently ignored when diagnosing rostral-caudal and caudal-rostral extraterritorial pain. Relating craniofacial pain to several pathologies such as cardiac ischemia, pulmonary thromboembolism, esophaguitis, head of the pancreas cancer, hepatitis or diverticulitis, could be seen as being mistaken, highlighting the lack of case reports or studies showing this and involving them with abdominal areas and the few reports regarding thoracic areas. Dull, diffuse and ambiguous (throbbing, tiring, cramping) and poorly localized pain which the vagus might produce could be the most important characteristic in the presence of craniofacial pain being referred from distant sites. Vagal deep pain induces a passive emotional coping behavior expressed as decrease reactivity to the situation (conservation-withdrawal reaction).

The vegetative effects of visceral-cardiac-respiratory centers being stimulated in pain are evident; as already mentioned, these can be anti-nociceptive and pro-nociceptive from craniofacial pain stimulus in pain facilitating centers, such as the dorsal-medullar reticular nucleus ultimately forging a balance of joint antagonic modulations in perceiving pain (Almeida et al.). The juxtaposition of cutaneous, mucocutaneous and visceral (cardiovascular) pain tracts at this level is unquestionable and explains nocifensive response to injury (Hubscher et al., 2004). This complex interaction between vegetative and sensory centers is important in both autonomic and affective responses to pain. Hypertension, asymptomatic myocardial ischemia and respiratory depression could be initiated in alterations to this system during chronic and deep pain, aiding a series of badly adapted disorders. The segmental and supra-segmental implications of chronic and deep pain have transcendental effects on localizing heterotopic pain via the effects of central sensitization, depending on the central level where they are found.

Sensory disorders, such as craniofacial and cervical referred pains can be perceived from distant and apparently unconnected sites, such as the caudal territories of the vagus. Such diagnosis depends on clinical acuteness and an extensive physical examination based on territorial coverage integrating different systems as a whole. The central nervous system's interaction with visceral-somatic afferents leads to a scale of ordered and adaptive responses orientated towards the body's dynamic equilibrium. The functional significance of such anatomical finding is an interesting topic; however, it has still not been resolved whether the signals produced in vagal afferents are able to auto-regulate or affect the whole organism via central feedback mechanisms in which the trigeminal nuclear complex is functionally involved. 
RAMIREZ, A. L. M.; BALLESTEROS, L. E.: FORERO, P. L. \& CONDE, C. Ganglio torácico vagal y dolor craneofacial referido. Reporte de caso y revisión. Int. J. Morphol., 25(1):33-42, 2007.

RESUMEN: Se reporta la presencia de una tumefacción a manera de "ganglio" en el trayecto mediastínico del nervio vago derecho, a nivel de T1, en un cadáver en el Laboratorio de Morfología de la Universidad Industrial de Santander, Colombia. El "ganglio" vagal se encuentra adyacente a nodos linfoides hiperplásicos, en niveles para-traqueales y traqueo-bronquiales que se aglomeran en una gran masa linfoide a la altura de la carina e hilio pulmonar. En el estudio anatomopatológico, se encontró marcado proceso inflamatorio mixto de predominio histo-linfocitario el cual se distribuye de manera difusa separando el epineuro y produciendo lisis de las fibras del nervio vago. Este hallazgo muestra la degeneración de este par craneal por patologías a nivel mediastínico. Esto brinda una posible explicación de la fisiopatología del dolor referido a cabeza y cuello, en patologías inflamatorias o neoplásicas que involucran la compresión y degeneración por infiltración inflamatoria del nervio vago. Se discute los tractos y la conectividad de las aferencias vagales a nivel ponto-medular, las vías supraespinales para el procesamiento del dolor sómato-visceral, las posibles respuestas sómato-vegetativas y la integración del sistema trigeminal en la fisiología del dolor en el nervio vago.

PALABRAS CLAVE: Viscerocepción; Dolor heterotópico; Ganglio inferior del nervio vago; Núcleo paratrigeminal; Subnucleus trigeminal caudal.

\section{REFERENCES}

Abraham, P.; Capobianco, D. J. \& Cheshire, W. P. Facial pain as the presenting symptom of lung carcinoma with normal chest radiograph. Headache, 43:499-504, 2003.

Adel, K. Afifi \& Ronald, A. Bergman. Functional Neuroanatomy: Text and Atlas. $2^{\mathrm{a}}$ ed. McGraw-Hill Edit; 2005.

Almeida, A.; Cobos, A.; Tavares, I. \& Lima, D. Brain afferents to the medullary dorsal reticular nucleus: a retrograde and anterograde tracing study in the rat. Eur. J. Neurosci., 16:8195, 2002.

Armstrong, C. L. \& Hopkins, D. A. Neurochemical organization of paratrigeminal nucleus projections to the dorsal vagal complex in the rat. Brain Res., 23:785:49-57, 1998.

Barry, J. J.; Lembke, A. \& Bullock, K. D. Current status of the utilization of antiepileptic treatments in mood, anxiety and aggression: drugs and devices. Clin. EEG. Neurosci., 35:413, 2004.

Beckstead, R. M. \& Norgren, R. An autoradiographic examination of the central distribution of the trigeminal, facial, glossopharyngeal, and vagal nerves in the monkey. J. Comp. Neurol., 184:455-72, 1979.

Berthoud, H. R. \& Neuhuber, W. L. Functional and chemical anatomy of the afferent vagal system. Auton. Neurosci., $85: 1-17,2000$.

Bindoff, L. A. \& Heseltine, D. Unilateral face pain in patients with lung cancer: A referred pain via the vagus? Lancet, $1: 812-5,1988$
Bon, K.; Lanteri-Minet, M. \& Menetrey, D. Involvement of the dorsal paratrigeminal nucleus in visceral pain-related phenomena. C. R. Acad. Sci., III, 320:607-13, 1997.

Bongers, K. M.;Willigers, H. M. \& Koehler, P. J. Referred pain from lung carcinoma. Neurology, 42:1841-2, 1992.

Bossut, D. F. \& Maixner, W. Effects of cardiac vagal afferent electrostimulation on the responses of trigeminal and trigeminothalamic neurons to noxious orofacial stimulation. Pain, 65:101-9, 1996.

Broux, R. Unilateral facial pain as the first symptom of lung cancer: A report of three cases. Cephalalgia, 11:319-20, 1991.

Capobianco, D. J. Facial pain as a symptom of nonmetastatic lung cancer. Headache, 35:581-5, 1995.

Caous, C. A. de Sousa Buck, H. \& Lindsey, C. J. Neuronal connections of the paratrigeminal nucleus: a topographic analysis of neurons projecting to bulbar, pontine and thalamic nuclei related to cardiovascular, respiratory and sensory functions. Auton. Neurosci., 94:14-24, 2001.

Carstens, E.; Saxe, I. \& Ralph, R. Brainstem neurons expressing c-Fos immunoreactivity following irritant chemical stimulation of the rat's tongue. Neuroscience, 69:939-53, 1995.

Casazza, M.; Avanzini, G.; Ferroli, P.; Villani, F. \& Broggi, G. Vagal nerve stimulation: relationship between outcome and electroclinical seizure pattern. Seizure, 15:198-207, 2006. 
Contreras, R. J.; Beckstead, R. M. \& Norgren, R. The central projections of the trigeminal, facial, glossopharyngeal and vagus nerves: an autoradiographic study in the rat. J. Auton. Nerv. Syst., 6:303-22, 1982.

Culberson, J. L. \& Kimmel, D. L. Central distribution of primary afferent fibers of the glossopharyngeal and vagal nerves in the opossum, Didelphis virginiana. Brain Res., 44:325-35, 1972.

Demez, P.; Goffart, Y. \& Daele, J. Facial pain from visceral origin. Acta Otorhinolaryngol. Belg., 58:141-2, 2004.

de Sousa Buck, H.; Caous, C. A \& Lindsey C. J. Projections of the paratrigeminal nucleus to the ambiguus, rostroventrolateral and lateral reticular nuclei, and the solitary tract. Auton. Neurosci., 87:187-200, 2001.

Des Prez, R. D. \& Freemon, F. R. Facial pain associated with lung cancer: a case report. Headache, 23:43-4, 1983.

Dodrill, C. B. \& Morris, G. L. Effects of vagal nerve stimulation on cognition and quality of life in epilepsy. Epilepsy Behav., 2:46-53, 2001.

Dunckley, P.; Wise, R. G.; Fairhurst, M.; Hobden, P.; Aziz, Q.; Chang, L. \& Tracey, I. A comparison of visceral and somatic pain processing in the human brainstem using functional magnetic resonance imaging. J. Neurosci., 25:7333-41, 2005.

Dutschmann, M. \& Herbert, H. NMDA and GABAA receptors in the rat Kolliker-Fuse area control cardiorespiratory responses evoked by trigeminal ethmoidal nerve stimulation. J. Physiol., 510:793-804, 1998.

Eross, E. J.; Dodick, D. W.; Swanson, J. W. \& Capobianco, D. J. A review of intractable facial pain secondary to underlying lung neoplasms. Cephalalgia, 23:2-5, 2003.

Fay, T. Atypical facial neuralgia. Ann. Otol. Rhinol. Laryngol., 41:1030-62, 1932.

Gieroba. Z. J. \& Blessing, W. W. Fos-containing neurons in medulla and pons after unilateral stimulation of the afferent abdominal vagus in conscious rabbits. Neuroscience, 59:851-58, 1994.

Goldberg, H. L. Chest cancer refers pain to face and jaw: A case review. J. Cranio. Pract., 15:167-9, 1997.

Gwyn, D. G.; Leslie, R. A. \& Hopkins, D. A. Observations on the afferent and efferent organization of the vagus nerve and the innervation of the stomach in the squirrel monkey. J. Comp. Neurol., 239:163-75, 1985.
Hisata, Y.; Zeredo, J. L.; Eishi, K. \& Toda, K. Cardiac nociceptors innervated by vagal afferents in rats. Auton. Neurosci., 126-127C:174-8, 2006.

Holzer, P. Neural injury, repair, and adaptation in the GI tract. II. The elusive action of capsaicin on the vagus nerve. Am. J. Physiol., 275:G8-13, 1998.

Hubscher, C. H.; Kaddumi, E. G. \& Jonson, R. D. Brain stem convergence of pelvis viscerosomatic inputs via spinal and vagal afferent. NeuroReport, 15:1299-302, 2004.

Jasmin, L.; Burkey, A. R.; Card, J. P. \& Basbaum, A. I. Transneuronal labeling of a nociceptive pathway, the spino(trigemino-) parabrachio-amygdaloid, in the rat. $J$. Neurosci., 17:3751-65, 1997.

Jones, M.T. \& Lawson, R. A. Unilateral face pain as a rare presentation of bronchial carcinoma. Br. J. Clin. Pract., 41:1025-26, 1987.

Jou, C. J. Farber, J. P.; Qin, C. \& Foreman, R. D. Convergent pathways for cardiac- and esophageal-somatic motor reflexes in rats. Autonom. Neurosci., 99:70-7, 2002.

Kalia, M. \& Mesulam, M. M. Brain stem projections of sensory and motor components of the vagus complex in the cat: I. The cervical vagus and nodose ganglion. J. Comp. Neurol., 193:435-65, 1980.

Khasar, S. G.; Miao, J. P.; Janig, W. \& Levine, J. D. Modulation of bradykinin-induced mechanical hyperalgesia in the rat by activity in abdominal vagal afferents. Eur. J. Neurosci., 10:435-44, 1998a.

Khasar, S. G.; Miao, F. J.; Janig, W. \& Levine, J. D. Vagotomyinduced enhancement of mechanical hyperalgesia in the rat is sympathoadrenal-mediated. J. Neurosci., 18:3043-9, 1998b.

Kirchner, A.; Stefan, H.; Bastian, K. \& Birklein, F. Vagus nerve stimulation suppresses pain but has limited effects on neurogenic inflammation in humans. Eur. J. Pain, 10:449$55,2006$.

Kobayashi, S.; Onimaru, H.; Inoue, M.; Inoue, T. \& Sasa, R. Localization and properties of respiratory neurons in the rostral pons of the newborn rat. Neuroscience, 134:317-25, 2005.

Lapa, R. C. \& Watanabe, I. Synaptic contacts established by inferior alveolar nerve fibres in the paratrigeminal nucleus: an electron microscopic study in the rat. Arch. Oral Biol., 50:73-9, 2005. 
Li, J. L.; Ding, Y. Q.; Shigemoto, R. \& Mizuno, N. Distribution of trigeminothalamic and spinothalamic-tract neurons showing substance P receptor-like immunoreactivity in the rat. Brain Res., 719:207-12, 1996.

Li, J. L.; Li, Y. Q.; Kaneko, T. \& Mizuno, N. Preprodynorphinlike immunoreactivity in medullary dorsal horn neurons projecting to the thalamic regions in the rat. Neurosci. Lett., 264:13-6, 1999.

Lindsey, C. J.; Buck, H. S.; Fior-Chadi, D. R. \& Lapa, R. C. Pressor effect mediated by bradykinin in the paratrigeminal nucleus of the rat. J. Physiol., 502:119-29, 1997.

Lund, J. P.; Lavigne, G. J.; Dubner, R. \& Sessle, B. J. Orofacial pain: From basic science to clinical management. 1st ed. Quintessence Publishing Co, Inc. Chicago, 2001.

Marfurt, C. F. \& Rajchert, D. M. Trigeminal primary afferent projections to "non-trigeminal" areas of the rat central nervous system. J. Comp. Neurol., 303:489$511,1991$.

Mauskop, A. Vagus nerve stimulation relieves chronic refractory migraine and cluster headaches. Cephalalgia, 25:82-6, 2005.

Melzack, R. From the gate to the neuromatrix. Pain, Suppl., 6:S121-6, 1999.

Menetrey, D.; De Pommery, J.; Baimbridge, K. G. \& Thomasset, M. Calbindin-D28K (CaBP28k)-like immunoreactivity in ascending projections. Eur. J. Neurosci., 4:61-9, 1992.

Miao, F. J.; Green, P.; Benowitz, N. \& Levine, J. D. Vagal modulation of spinal nicotine-induced inhibition of the inflammatory response mediated by descending antinociceptive controls. Neuropharmacology, 45:605-11, 2003.

Monconduit, L.; Bourgeais, L.; Bernard, J. F. \& Villanueva, L. Convergence of cutaneous, muscular and visceral noxious inputs onto ventromedial thalamic neurons in the rat. Pain, 103:83-91, 2003.

Mtui, E. P.; Anwar, M.; Reis, D. J. \& Ruggiero, D. A. Medullary visceral reflex circuits: local afferents to nucleus tractus solitarii synthesize catecholamines and project to thoracic spinal cord. J. Comp. Neurol., 351:5-26, 1995.

Nasution, I. D. \& Shigenaga, Y. Ascending and descending internuclear projections within the trigeminal sensory nuclear complex. Brain Res., 425:234-47, 1987.
Ness, T. J. \& Gebhart, G. F. Interactions between visceral and cutaneous nociception in the rat. I. Noxious cutaneous stimuli inhibit visceral nocicetive neurons and reflexes. J. Neurophysiol., 66:20-8, 1991a.

Ness, T. J. \& Gebhart, G. F. Interactions between visceral and cutaneous nociception in the rat. II. Noxious visceral stimuli inhibit cutaneous nociceptive neurons and reflexes. J. Neurophysiol., 66:29-39, 1991b.

Ness, T. J.; Fillingim, R. B.; Randich, A.; Backensto, E. M. \& Faught, E. Low intensity vagal nerve stimulation lowers human thermal pain thresholds. Pain, 86:81-5, 2000.

Nestor, J. J. Unilateral facial pain in lung cancer. Lancet, 338:1149, 1991.

Nestor, J. J. \& Ngo, L. K. Incidence of facial pain caused by lung cancer. Otolaryngol. Head Neck Surg., 111:155-6, 1994.

O'Keane, V.; Dinan, T. G.; Scott, L. \& Corcoran, C. Changes in hypothalamic-pituitary-adrenal axis measures after vagus nerve stimulation therapy in chronic depression. Biol. Psychiatry, 58:963-8, 2005.

Palmieri, A. Lung cancer presenting with unilateral facial pain: remission after laryngeal nerve palsy. Headache, 46:8135, 2006 .

Phelan, K. D. \& Falls, W. M. The interstitial system of the spinal trigeminal tract in the rat: anatomical evidence for morphological and functional heterogeneity. Somatosens Mot. Res., 6:367-99, 1989.

Phelan, K. D. \& Falls, W. M. The spinotrigeminal pathway and its spatial relationship to the origin of trigeminospinal projections in the rat. Neuroscience, 40:477-96, 1991.

Paues, J.; Mackerlova, L. \& Blomqvist, A. Expression of melanocortin-4 receptor by rat parabrachial neurons responsive to immune and aversive stimuli. Neuroscience, 141:287-97, 2006.

Randich, A. \& Gebhart, G. F. Vagal afferent modulation of nociception. Brain Res. Rev., 17:77-99, 1992.

Ruggiero, D. A.; Underwood, M. D.; Mann, J. J.; Anwar, M. \& Arango, V. The human nucleus of the solitary tract: visceral pathways revealed with an "in vitro" postmortem tracing method. J. Auton. Nerv. Syst., 79:181-90, 2000.

Rybka, E. J. \& McCulloch, P. F. The anterior ethmoidal nerve is necessary for the initiation of the nasopharyngeal response in the rat. Brain Res., 23(1075):122-32, 2006. 
Sandkuhler, J. The organization and function of endogenous antinociceptive systems. Prog. Neurobiol., 50:49-81, 1996.

Saper, C. B. The spinoparabrachial pathway: Shedding new light on an old path. J. Comp. Neurol., 353:477-9, 1995.

Sarlani, E.; Schwartz, A. H.; Greenspan, J. D. \& Grace, E. G. Facial pain as first manifestation of lung cancer: A case of lung cancer related cluster headache and a review of the literature. J. Orofac. Pain, 17:262-7, 2003.

Sato, K. \& Momose-Sato, Y. Optical detection of convergent projections in the embryonic chick NTS. Neurosci. Lett., 371:97-101, 2004.

Saxon, D.W. \& Hopkins, D. A. Efferent and collateral organization of paratrigeminal nucleus projections: an anterograde and retrograde fluorescent tracer study in the rat. J. Comp. Neurol., 402:93-110, 1998.

Saxon, D. W. \& Hopkins, D. A. Ultrastructure and synaptology of the paratrigeminal nucleus in the rat: primary pharyngeal and laryngeal afferent projections. Synapse, 59:220-34, 2006.

Sedan, O.; Sprecher, E. \& Yarnitsky, D. Vagal stomach afferents inhibit somatic pain perception. Pain, 113:354-9, 2005.

Shakespeare, T. P. \& Stevens, M. J. Unilateral face pain in lung cancer. Aust. Radiol., 40:45-6, 1996.

Schoenen, J.; Broux, R. \& Moonen, G. Unilateral facial pain as the first symptom of lung cancer: are there diagnostic clues? Cephalalgia, 12:178-9, 1992.

Sessle, B. J. Acute and chronic craniofacial pain: Brain stem mechanism of nociceptive transmission and neuroplasticity and their clinical correlates. Crit. Rev. Oral Biol. Med., 11:57-91, 2000.

Stuesse, S. L.; Cruce, W. L. \& Powell, K. S. Organization within the cranial IX-X complex in ranid frogs: a horseradish peroxidase transport study. J. Comp. Neurol., 222:358-65, 1984.

Tanimoto, T.; Takeda, M. \& Matsumoto, S. Suppressive effect of vagal afferents on cervical dorsal horn neurons responding to tooth pulp electrical stimulation in the rat. Exp. Brain Res., 145:468-79, 2002.

Than, M.; Nemeth. J.; Szilvassy, Z.; Pinter, E.; Helyes, Z. \& Szolcsanyi, J. Systemic anti-inflammatory effect of somatostatin released from capsaicin-sensitive vagal and sciatic sensory fibres of the rat and guinea-pig. Eur. J. Pharmacol., 399:251-8, 2000.
Traub, R. J.; Sengupta, J. N. \& Gebhart, G. F. Differential c-fos expression in the nucleus of the solitary tract and spinal cord following noxious gastric distension in the rat. Neuroscience, 74:873-84, 1996.

Wand-Tetley, J. I. Historical methods of counter-irritation. Ann. Phys. Med., 3:90-9, 1956.

Wheless, J. W. \& Baumgartner, J. Vagus nerve stimulation therapy. Drugs Today (Barc.), 40:501-15, 2004.

Williams, P. L.; Warwick, R.; Dyson, M. \& Bannister, L. H. Gray's anatomy. 37th ed. Edinburgh, Scotland, Churchill Livingston, 1989.

Yousfi-Malki, M. \& Puizillout, J. J. Induction of Fos-like protein in neurons of the medulla oblongata after electrical stimulation of the vagus nerve in anesthetized rabbit. Brain Res., 635:317-22, 1994.

Correspondence to:

Dr. Luis Miguel Ramírez Aristeguieta

Associate Professor of Morphology

Department of Basic Sciences

Medicine Faculty

Universidad Industrial de Santander

Bucaramanga

COLOMBIA

Fax: (097) 6479668

Email: Imra3@yahoo.com

Received: 20-07-2006

Accepted: 14-10-2006 